\title{
ANALISIS PENGARUH INDEKS WALKABILITY TERHADAP KEINGINAN BERJALAN KAKI DARI DAN MENUJU STASIUN TRANSPORTASI UMUM
}

\author{
Reynaldo Bernard Khuana ${ }^{1}$ dan Leksmono Suryo Putranto ${ }^{2}$
}

\author{
${ }^{1}$ Program Studi Sarjana Teknik Sipil, Universitas Tarumanagara, Jl. Letjen S. Parman No.1 Jakarta \\ reynaldo.325160004@stu.untar.ac.id \\ ${ }^{1}$ Program Studi Sarjana Teknik Sipil, Universitas Tarumanagara, Jl. Letjen S. Parman No.1 Jakarta \\ leksmonop@ft.untar.ac.id
}

Masuk: 15-07-2021, revisi: 25-08-2021, diterima untuk diterbitkan: 31-08-2021

\begin{abstract}
Although the construction of public transport infrastructure is underway, the poor quality of the pedestrian paths may result in users being reluctant to use public transport. Therefore, a method to find out the walking path according to the user's desire to travel is needed. This study aims to determine the factors formed and the influence of socials-demographic characteristics on the desire to walk to and from public transportation stations in Indonesia. The statements contained in the questionnaire were made based on the walkability index that has been used previously in several countries and confirmed by factor analysis. The results of the factor analysis showed that from the 13 variables tested, there were 4 variables which were reduced until the remaining 9 variables formed 2 factors. The two factors are the convenience factor and the practicality and safety factor. socialsdemographic factors such as age, gender, walking frequency, walking distance, place of residence, walking purpose, and monthly expenses did not have a significant influence on the pleasantness factor as well as the practicability and safety factor.
\end{abstract}

Keywords: walkability; desire to walk; safety; practicability; pleasantness

\begin{abstract}
ABSTRAK
Meskipun pembangunan infrastruktur transportasi umum sedang dilakukan, kualitas jalur pejalan kaki yang buruk dapat mengakibatkan pengguna enggan untuk menggunakan transportasi umum. Oleh karena itu suatu metode untuk mengetahui jalur perjalan kaki yang sesuai dengan keinginan berjalan pengguna sangatlah diperlukan. Penelitian ini bertujuan untuk mengetahui faktor-faktor yang terbentuk dan pengaruh karakteristik sosialdemografis terhadap keinginan berjalan kaki dari dan menuju stasiun transportasi umum di Indonesia. Pernyataanpernyataan yang terdapat dari kuesioner dibuat berdasarkan indeks walkability yang telah digunakan sebelumnya pada beberapa negara dan dikonfirmasi dengan analisis faktor. Hasil analisis faktor menunjukkan dari 13 variabel yang diuji terdapat 4 variabel yang direduksi hingga tersisa 9 variabel yang membentuk 2 faktor. Kedua faktor tersebut adalah faktor kenyamanan dan faktor kepraktisan dan keselamatan. faktor sosial-demografis seperti usia, jenis kelamin, frekuensi berjalan kaki, jarak kemampuan berjalan, tempat tinggal, tujuan berjalan, dan pengeluaran tiap bulan tidak memberikan pengaruh yang signifikan terhadap faktor kenyamanan maupun faktor kenyamanan dan keselamatan.
\end{abstract}

Kata kunci: walkability; keinginan berjalan kaki; keselamatan; kepraktisan; kenyamanan

\section{PENDAHULUAN}

Pada saat ini, pembangunan transportasi umum sangatlah gencar dilakukan di Indonesia. Hal ini bertujuan untuk mengurangi kemacetan lalu lintas dan polusi udara. Secara ekonomi, transportasi umum juga dapat mempermudah akses masyarakat sehingga dapat meningkatkan produktivitas, mempercepat perkembangan dan nilai jual suatu daerah/ kota. Secara sosial dan budaya, transportasi umum bertujuan untuk pemerataan akses pada pelayanan dasar sehingga tidak terjadi kesenjangan akses dari distribusi sumberdaya untuk mengurangi kemiskinan.

Menurut Schafer (1998) Sistem transportasi umum memberikan kontribusi positif terhadap keberlanjutan ekonomi, sosial budaya, dan lingkungan hidup dari komunitas yang dilayani. Keberadaan sistem transportasi adalah untuk memenuhi kebutuhan keterkaitan ekonomi dan sosial serta memberikan kesempatan kepada masyarakat untuk meningkatkan mobilitas. Manfaat dari peningkatan mobilitas dalam transportasi untuk kepentingan publik adalah untuk mengurangi dampak negatif terhadap aspek ekonomi, sosial, dan lingkungan. 
Namun, pembangunan transportasi umum tidaklah efektif tanpa didukung oleh jalur khusus yang memadai bagi pejalan kaki untuk menuju stasiun transportasi umum. Terlepas dari itu, lingkungan yang dibangun di sekitar stasiun transportasi umum yang bersih dan aman juga sangatlah penting untuk menunjang keberhasilan suatu stasiun transportasi umum.

Hampir semua perjalanan antara asal dan tujuan pasti membutuhkan berjalan. Berjalan kaki sebagai alat transportasi biasanya digunakan dalam perjalanan singkat atau sebagai penunjang bagi alternatif transportasi lainnya. Oleh karena itu, jalur pejalan kaki mendapat peran yang cukup vital dalam menunjang keberhasilan dari stasiun transportasi umum terutama di kota- kota besar yang memiliki aktivitas perkantoran tinggi seperti Jakarta, Tangerang, Bogor dan lainnya (Jabodetabek). Jalur pejalan kaki yang tidak kompatibel dan tidak proposional akan berpengaruh buruk bagi para pejalan kaki dan juga dapat mempengaruhi moda transportasi umum lainnya.

Berjalan kaki merupakan hak bagi semua orang, maka pembangunan jalur khusus yang aman, nyaman, dan terawat bagi pejalan kaki sangatlah diperlukan. Jalur ini dapat berupa trotoar, zebra cross, dan jembatan penyebrangan. Sejauh ini, Pemerintah telah memperbesar dan membangun jalur-jalur baru untuk kenyamanan pejalan kaki yang juga bertujuan untuk menunjang efektifitas dari moda transportasi lainnya.

\section{Transportasi umum}

Menururt McLeod et al, 2017. Moda transportasi umum adalah layanan angkutan penumpang oleh sistem perjalanan kelompok yang tersedia untuk digunakan oleh masyarakat umum. Moda transportasi umum diantaranya adalah bus kota, trem (kereta api ringan) dan kereta api, kereta api cepat, serta feri.

Pada penelitian kali ini penulis membatasi transportasi umum yang dimaksud adalah bus kota, trem (kereta api ringan) dan kereta api, kereta api cepat. Untuk transportasi umum laut dan udara penulis tidak memasukkan kedalam penelitian.

\section{Moda berjalan kaki}

Berjalan adalah suatu kegiatan yang menggunakan kaki sebagai alat bergerak, dan merupakan salah satu moda yang sering dilakukan oleh orang untuk mencapai tempat tujuan terutama tempat yang jaraknya dekat dengan tempat tujuan. Dalam beberapa kasus lain, berjalan tidak selalu menggunakan kaki. Bagi penyandang disabilitas, menggunakan kursi roda pun termasuk dalam aktifitas berjalan. Selain itu kegiatan perpindahan yang dilakukan dengan menumpang orang yang berjalan seperti digendong atau ditandu juga termasuk kategori pejalan.

Berjalan merupakan salah satu elemen yang turut mendukung sistem kota secara keseluruhan, terutama di kawasan pusat kota atau kawasan dalam batas kemampuan orang berjalan. Munculnya kebutuhan akan berjalan sebenarnya sama dengan kebutuhan akan permintaan perangkutan atau kebutuhan transportasi. Aktivitas kota akan menimbulkan permintaan akan sistem transportasi beserta modanya, apabila lokasi aktifitas tersebut dapat dijangkau. Terkadang beberapa kegiatan hanya dapat dilakukan dengan berjalan karena terbatasnya kemampuan moda transportasi atau karena keadaan suatu kawasan yang tidak memungkinkan moda transportasi memasukinya. Berjalan dapat dianggap sebagai alat pendukung sistem transportasi.

Berdasarkan jenis perjalanan yang dilakukan, tingkat penggunaan moda berjalan dapat dibagi menjadi dua, yaitu sebagai moda utama dan sebagai moda antara. Berjalan digolongkan sebagai moda utama dalam perjalanan jika pergerakan yang dilakukan dari tempat asal hingga tempat tujuan dilakukan seluruhnya atau Sebagian besar dengan jalan kaki. Sedangkan berjalan digolongkan sebagai moda antara apabila dari tempat asal ke tempat tujuan turut menggunakan moda transportasi lainnya dengan proporsi lebih banyak dibandingkan berjalan.

Pejalan kaki adalah orang yang melakukan aktivitas berjalan dan merupakan salah satu unsur pengguna jalan (Kusbiantoro,2006). Untuk keperluan dan keselamatan perjalan kaki dibutuhkan beberapa fasilitas. Jenis fasilitas yang dibutuhkan oleh pejalan kaki tersebut beberapa diantaranya adalah trotoar, zebracross, jembatan penyebrangan dan terowongan penyebrangan.

\section{Indeks walkability}

Walkability adalah sebuah ukuran seberapa ramah suatu area untuk dapat dilalui dengan berjalan kaki. Salah satu defenisi walkability adalah sejauh mana lingkungan binaan ramah terhadap keberadaan orang yang tinggal, berbelanja, berkunjung, menikmati atau bahkan menghabiskan waktu di suatu daerah. Banyak sekali kriteria yang harus diperhitungkan dalam mengevaluasi walkability, dan berbagai indikator harus dinilai karena memiliki dampak yang berbeda terhadap walkability dan pada pilihan rute. Oleh sebab itu indikator dikelompokan menjadi 3 faktor (D'orso dan Migliore,2020):

- Kepraktisan (practicability), yang memperhatikan kondisi dan pembersihan trotoar, penghalang arsitektur, dan semua elemen lain yang membatasi aksesibilitas. 
- Keselamatan (safety), mencakup indikator yang berhubungan dengan perlindungan dari berbagai resiko selama pengalaman berjalan, seperti keberadaan penghalang untuk perlindungan pejalan kaki dari kendaraan, penerangan jalan, dan persepsi keamanan terhadap kejahatan

- Kesenangan (pleasantness), yang berkaitan dengan daya tarik jalan dan kehadiran furnitur jalan guna meningkatkan derajat berjalan.

Salah satu cara untuk menilai dan mengukur kawasan untuk berjalan kaki adalah dengan melakukan audit berjalan. Alat ukur audit berjalan yang mapan dan paling banyak digunakan adalah dengan PERS (Pedestrian Environment Review System) yang telah dipergunakan luas di Inggris.

Cara sederhana untuk menentukan kualitas berjalan kaki sebuah blok, koridor, atau lingkungan yakni dengan cara menghitung jumlah orang yang berjalan, jumlah orang yang bertahan dan terlibat dalam aktivitas opsional dalam sebuah ruangan. Proses ini merupakan perbaikan besar pada indikator tingkat layanan pejalan kaki (LOS).

\section{METODE PENELITIAN}

Metode penelitian yang akan digunakan dalam penelitian ini adalah metode kuantitatif. Penelitian ini mendasarkan pada perhitungan angka-angka atau statistik. Pada penelitian ini dilakukan analisis terhadap indikator-indikator walkability terhadap kesediaan berjalan dari dan menuju stasiun transportasi umum. Data tersebut didapatkan dengan menggunakan metode kuesioner. Kuesioner yang dijalankan bersifat daring melalui aplikasi Google form.

Target responden dari kuesioner adalah pengguna transportasi umum yang berdomisili di JABODETABEK (Jakarta, Bogor, Depok, Tangerang, dan Bekasi). Dari pengolahan data kuesioner maka didapat informasi mengenai keterkaitan antara indikator-indikator walkability terhadap kesediaan berjalan dari dan menuju stasiun transportasi umum.

Untuk menguji validitas dan reliabilitas kuesioner, dilakukan uji coba kepada 20 responden. Setelah memperbaiki kalimat pertanyaan yang tidak valid dan tidak reliabel, final kuesioner kemudian dibagikan kepada 150 responden. Skala yang digunakan dalam kuesioner adalah skala likert. Responden diminta untuk menilai apakah mereka sangat tidak setuju (1), tidak setuju (2), setuju (3), atau sangat setuju (4) di setiap pertanyaan kuesioner. Kuesioner dalam penelitian ini terdapat dua bagian. Bagian pertama berisi pertanyaan tentang demografis dan karakteristik sosial, seperti usia, jenis kelamin, frekuensi berjalan kaki, jarak kemampuan berjalan, tempat tinggal, tujuan berjalan, dan pengeluaran tiap bulan. Bagian kedua berisi 13 pernyataan indeks walkability yang diadaptasi dari penelitian D'orso et al.(2020), yang dibagi menjadi tiga faktor yaitu faktor kenyamanan (5 variabel), faktor kepraktisan (4 variabel), dan faktor keamanan (5 variabel)

Alur atau tahapan dari penelitian ini digambarkan dalam diagram seperti pada gambar 1 sebagai berikut. 


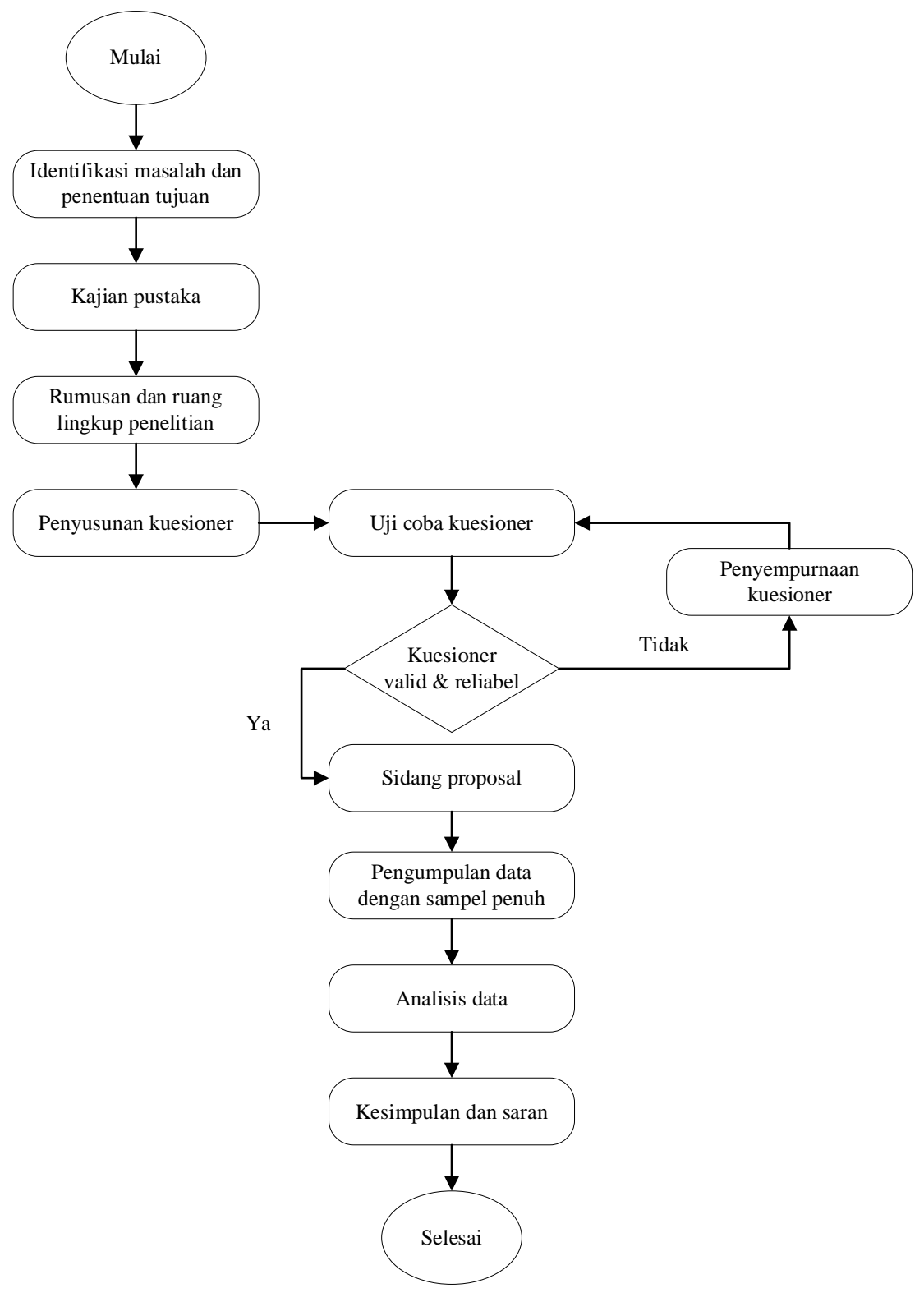

Gambar 1. Diagram alur penelitian

Kuesioner sementara yang diuji pada 20 responden digunakan untuk melakukan uji validitas dan reliabilitas. Uji validitas dilakukan untuk mengetahui apakah butir pertanyaan dalam kuesioner sudah valid atau belum untuk mengukur variabel yang akan diteliti. Uji validitas dilakukan dengan menggunakan teknik korelasi Spearman dengan tingkat signifikan $<0,05$ dinyatakan valid. Sedangkan uji reliabilitas dilakukan untuk mengetahui konsistensi hasil pengukuran apabila dilakukan pengukuran dua kali atau lebih terhadap gejala yang sama dengan menggunakan alat pengukur yang sama pula. Uji reliabilitas dilakukan dengan metode Cronbach's Alpha dengan tingkat signifikan $>0,60$ dinyatakan reliabel. Dalam hasil analisis uji coba kuesioner terdapat satu item pada faktor kenyamanan dinyatakan tidak valid. hasilnya kuesioner diputuskan untuk tidak merubah kalimat pada item tersebut karena jumlah sampel yang dikumpulkan masih kurang dari jumlah minimum sampel. Dengan sampel penuh, 150 responden, semua item dinyatakan valid. Namun, hasil uji reliabilitas pada faktor kepraktisan dan keselamatan dinyatakan tidak reliabel $(<0,60)$ sehingga disarankan bagi yang membaca untuk mempertimbangkan kembali dalam menggunakan item pada pertanyaan ini dengan bijak. Setelah dilakukan uji validitas dan reliabilitas, lalu dilanjutkan dengan analisis faktor. IBM SPSS Statistics 25 digunakan untuk membantu menganalisis hasil penelitian.

Pada hasil analisis faktor yang dilakukan Putranto dan Khuana (2021) ada beberapa item yang dihilangkan karena nilai MSA (Measure of Sampling Adequacy) < 0,5. Setelah dilakukan 3 (tiga) kali percobaan, hasil akhir menunjukkan nilai Kaiser-Meyer-Olkin Measure of Sampling Adequacy sebesar 0,794 (> 0,6) dan nilai signifikansi Bartlett's Test of Sphericity kurang dari 0,001. Dari ke-13 item indeks walkability 4 (empat) item yang 
direduksi. Hasil akhir menunjukkan 9 item yang mempengaruhi keinginan berjalan kaki dari dan menuju stasiun transportasi umum. Dari hasil ini membentuk 2 (dua) faktor perilaku pejalan kaki di Indonesia yaitu faktor kenyamanan-kepraktisan dan faktor kepraktisan-keselamatan. Total kedua faktor yang terbentuk mampu menjelaskan variabel sebesar 73,113\%. Item dan nilai loading factor perilaku pejalan kaki dapat dilihat pada tabel 1. Setelah dilakukan analisis faktor, dilanjutkan dengan uji selisih rataan guna mengetahui pengaruh demografis terhadap perilaku pejalan kaki di Indonesia.

Tabel 1. Item dan loading factor keinginan berjalan kaki dari dan menuju stasiun transportasi umum di Indonesia

\begin{tabular}{|c|c|c|c|}
\hline & \multirow[b]{2}{*}{ ITEM } & \multicolumn{2}{|c|}{ LOADING FACTOR } \\
\hline & & $\begin{array}{l}\text { FAKTOR } \\
\text { KENYAMANAN- } \\
\text { KEPRAKTISAN } \\
\end{array}$ & $\begin{array}{l}\text { FAKTOR } \\
\text { KEPRAKTISAN- } \\
\text { KESELAMATAN }\end{array}$ \\
\hline A. 2 & $\begin{array}{l}\text { saya lebih ingin berjalan kaki apabila terdapat } \\
\text { tanaman hijau pada jalan yang saya lewati }\end{array}$ & 0,88 & \\
\hline A. 3 & $\begin{array}{l}\text { saya lebih ingin berjalan kaki apabila terdapat } \\
\text { tempat berteduh dari sinar matahari/hujan bagi } \\
\text { pejalan kaki }\end{array}$ & 0,862 & \\
\hline A. 4 & $\begin{array}{l}\text { saya lebih ingin berjalan kaki apabila terdapat } \\
\text { fasilitas untuk pejalan kaki yang memadai } \\
\text { (kursi, keranjang sampah,dll) }\end{array}$ & 0,735 & \\
\hline A. 5 & $\begin{array}{l}\text { saya lebih ingin berjalan kaki apabila } \\
\text { bangunan yang saya lewati bersih dan terawat } \\
\text { permukaannya. }\end{array}$ & 0,885 & \\
\hline B. 1 & $\begin{array}{l}\text { saya lebih ingin berjalan kaki apabila jalur } \\
\text { pejalan kaki (trotoar) dapat dengan mudah } \\
\text { digunakan untuk berbagai kalangan. }\end{array}$ & 0,848 & \\
\hline B. 2 & $\begin{array}{l}\text { saya lebih menyukai berjalan di trotoar yang } \\
\text { lebar }\end{array}$ & & 0,917 \\
\hline B. 3 & $\begin{array}{l}\text { saya lebih menyukai berjalan di trotoar yang } \\
\text { tidak terdapat hambatan }\end{array}$ & & 0,787 \\
\hline C. 3 & $\begin{array}{l}\text { saya merasa lebih aman apabila berjalan di } \\
\text { trotoar yang terdapat pemisah antara trotoar } \\
\text { dan jalan }\end{array}$ & & 0,91 \\
\hline C. 4 & $\begin{array}{l}\text { saya merasa lebih aman apabila berjalan di } \\
\text { jalan yang terdapat lampu lalulintas di } \\
\text { simpang, sehingga saya dapat menyeberang } \\
\text { dengan aman. }\end{array}$ & & 0,832 \\
\hline
\end{tabular}

(Sumber : Putranto dan Khuana, 2021)

\section{HASIL DAN PEMBAHASAN}

Untuk mengetahui apakah adanya pengaruh demografis terhadap perilaku pejalan kaki Indonesia atau tidak, dilakukan uji selisih rataan. Adanya perbedaan rataan yang nyata atau tidak dilihat dari nilai signifikansi pada tabel independent sample t-test. Independent sample t-test merupakan t-test yang dilakukan dengan membandingkan rataan dua kelompok data. Nilai signifikan kurang dari 0,05 maka dikatakan adanya perbedaan rataan antara kedua variabel yang diteliti. Hasil uji selisih rataan untuk kelompok usia, jenis kelamin, tempat tinggal, dan frekuensi penggunaan transportasi umum dapat dilihat pada tabel 2 sampai dengan tabel 5. 
Tabel 2 Skor selisih rataan dari kelompok usia

\begin{tabular}{cccc}
\hline \multirow{2}{*}{ Usia } & $\mathrm{N}$ & \multicolumn{2}{c}{ Skor Selisih Rataan } \\
\cline { 3 - 4 } & & $\begin{array}{c}\text { Faktor } \\
\text { Kenyamanan }\end{array}$ & $\begin{array}{c}\text { Faktor Kepraktisan dan } \\
\text { Keselamatan }\end{array}$ \\
\hline <40 Tahun & 109 & 3,7009 & 3,6353 \\
$\geq 40$ Tahun & 41 & 3,4634 & 3,6951 \\
Selisih Rataan & & 0,2375 & $-0,05980$ \\
Tingkat Signifikan & & 0,055 & 0,471 \\
Signifikan? & & Tidak & Tidak \\
(Ya/Tidak) & & &
\end{tabular}

Tabel 3 Skor selisih rataan dari kelompok perbedaan jenis kelamin

\begin{tabular}{cccc}
\hline & & \multicolumn{2}{c}{ Skor Selisih Rataan } \\
\cline { 3 - 4 } Jenis Kelamin & $\mathrm{N}$ & $\begin{array}{c}\text { Faktor } \\
\text { Kenyamanan }\end{array}$ & $\begin{array}{c}\text { Faktor Kepraktisan dan } \\
\text { Keselamatan }\end{array}$ \\
\hline Laki-laki & 64 & 3,6188 & 3,7070 \\
Perempuan & 86 & 3,6488 & 3,6105 \\
Selisih Rataan & & $-0,03009$ & 0,09657 \\
Tingkat Signifikan & & 0,755 & 0,190 \\
Signifikan? & & Tidak & Tidak \\
(Ya/Tidak) & & &
\end{tabular}

Tabel 4 Skor selisih rataan dari kelompok perbedaan tempat tinggal

\begin{tabular}{cccc}
\hline & & \multicolumn{2}{c}{ Skor Selisih Rataan } \\
\cline { 3 - 4 } Tempat Tinggal & $\mathrm{N}$ & $\begin{array}{c}\text { Faktor } \\
\text { Kenyamanan }\end{array}$ & $\begin{array}{c}\text { Faktor Kepraktisan dan } \\
\text { Keselamatan }\end{array}$ \\
\hline Jakarta & 112 & 3,6161 & 3,6573 \\
Non-Jakarta & 38 & 3,6947 & 3,6645 \\
Selisih Rataan & & $-0,07867$ & $-0,01715$ \\
Tingkat Signifikan & & 0,473 & 0,840 \\
Signifikan? & & Tidak & Tidak \\
(Ya/Tidak) & & &
\end{tabular}

Tabel 5 Skor selisih rataan dari kelompok perbedaan frekuensi penggunaan transportasi umum

\begin{tabular}{cccc} 
Frekuensi & & \multicolumn{2}{c}{ Skor Selisih Rataan } \\
\cline { 3 - 4 } $\begin{array}{c}\text { Penggunaan } \\
\text { Transportasi Umum }\end{array}$ & $\mathrm{N}$ & $\begin{array}{c}\text { Faktor } \\
\text { Kenyamanan }\end{array}$ & $\begin{array}{c}\text { Faktor Kepraktisan dan } \\
\text { Keselamatan }\end{array}$ \\
\hline $\begin{array}{c}\text { 5 kali atau lebih } \\
\text { dalam 1 minggu }\end{array}$ & 29 & 3,6552 & 3,6379 \\
Kurang dari 5 kali & 121 & 3,6314 & 3,6550 \\
dalam 1 minggu & & 0,02377 & $-0,01703$ \\
$\begin{array}{c}\text { Selisih Rataan } \\
\text { Tingkat Signifikan }\end{array}$ & & 0,844 & 0,856 \\
$\begin{array}{c}\text { Signifikan? } \\
\text { (Ya/Tidak) }\end{array}$ & & Tidak & Tidak \\
\hline
\end{tabular}

Dari hasil uji selisih rataan pada tabel 2 sampai dengan tabel 5, kelompok yang diuji tidak memiliki pengaruh signifikan terhadap faktor-faktor yang mempengaruhi keinginan berjalan kaki dari dan menuju stasiun transportasi 
umum di Indonesia. Hal tersebut dibuktikan dengan nilai pada tingkat signifikan $\geq 0.05$. Pada tabel 6 sampai 8 berikut adalah skor selisih rataan berdasarkan beberapa kriteria.

Tabel 6 Skor selisih rataan dari kelompok perbedaan jarak kemampuan berjalan kaki

\begin{tabular}{cccc}
\hline $\begin{array}{c}\text { Jarak Kemampuan } \\
\text { Berjalan }\end{array}$ & $\mathrm{N}$ & \multicolumn{2}{c}{ Skor Selisih Rataan } \\
\cline { 3 - 4 } & 99 & 3,6902 & $\begin{array}{c}\text { Faktor } \\
\text { Kenyamanan }\end{array}$ \\
\hline$<1000 \mathrm{~m}$ & 31 & 3,6081 & 3,6324 \\
$\geq 1000 \mathrm{~m}$ & $-0,08212$ & 3,6616 \\
Selisih Rataan & & 0,414 & 0,02926 \\
Tingkat Signifikan & & Tidak & 0,708 \\
Signifikan? & & & Tidak \\
(Ya/Tidak) & & &
\end{tabular}

Tabel 7 Skor selisih rataan dari kelompok perbedaan pengeluaran biaya perbulan

\begin{tabular}{cccc}
\hline $\begin{array}{c}\text { Pengeluaran per } \\
\text { Bulan }\end{array}$ & $\mathrm{N}$ & \multicolumn{2}{c}{ Skor Selisih Rataan } \\
\cline { 3 - 4 } & & $\begin{array}{c}\text { Faktor } \\
\text { Kenyamanan }\end{array}$ & $\begin{array}{c}\text { Faktor Kepraktisan dan } \\
\text { Keselamatan }\end{array}$ \\
\hline$<$ Rp 4.500.000 & 101 & 3,6594 & 3,6411 \\
$\geq$ Rp 4.500.000 & 49 & 3,5878 & 3,6735 \\
Selisih Rataan & & $-0,07165$ & 0,03238 \\
Tingkat Signifikan & & 0,481 & 0,682 \\
Signifikan? & & Tidak & Tidak \\
(Ya/Tidak) & & &
\end{tabular}

Tabel 8 Skor selisih rataan dari kelompok perbedaan tujuan perjalanan menggunakan transportasi umum

\begin{tabular}{cccc}
\hline & & \multicolumn{2}{c}{ Skor Selisih Rataan } \\
\cline { 3 - 4 } Tujuan Perjalanan & $\mathrm{N}$ & $\begin{array}{c}\text { Faktor } \\
\text { Kenyamanan }\end{array}$ & $\begin{array}{c}\text { Faktor Kepraktisan dan } \\
\text { Keselamatan }\end{array}$ \\
\hline Bekerja & 64 & 3,5313 & 3,6484 \\
Lain-Lain & 86 & 3,7140 & 3,6541 \\
Selisih Rataan & & $-0,18270$ & $-0,00563$ \\
Tingkat Signifikan & & 0,070 & 0,940 \\
Signifikan? & & Tidak & Tidak \\
(Ya/Tidak) & & &
\end{tabular}

Dari tabel 6 sampai dengan tabel 8 diatas, dapat dilihat bahwa kelompok jarak kemampuan berjalan kaki, pengeluaran biaya perbulan, dan tujuan penggunaan transportasi yang diuji pada penelitian tidak memiliki pengaruh yang signifikan terhadap kedua faktor keinginan berjalan kaki dari dan menuju transportasi umum di Indonesia. Hal ini dibuktikan dengan nilai signifikan yang tertera pada tiap faktor yang diuji terhadap faktor keinginan berjalan kaki dari dan menuju stasiun transportasi umum tidak ada yang kurang dari 0,05.

\section{KESIMPULAN DAN SARAN}

\section{Kesimpulan}

Berdasarkan penelitian yang telah dilakukan dapat disimpulkan bahwa keinginan berjalan kaki dari dan menuju stasiun transportasi umum di Indonesia dipengaruhi oleh dua faktor yaitu faktor kenyamanan-kepraktisan dan faktor kepraktisan dan keselamatan. faktor yang didapat sudah reliabel dan valid sehingga dapat digunakan untuk penelitian-penelitian kedepannya. 
Faktor-faktor lain yang diuji seperti seperti usia, jenis kelamin, frekuensi berjalan kaki, jarak kemampuan berjalan, tempat tinggal, tujuan berjalan, dan pengeluaran tiap bulan pada penelitian ini terbukti tidak memiliki pengaruh yang signifikan terhadap keinginan berjalan kaki dari dan menuju stasiun transportasi umum di Indonesia.

\section{Saran}

Penelitian ini menjabarkan faktor dan variabel apa saja yang memiliki pengaruh yang signifikan terhadap keinginan berjalan kaki dari dan menuju stasiun transportasi umum. Hasil penelitian ini dapat menjadi salah satu acuan dalam pembangunan infrastruktur transportasi umum dengan tujuan untuk mengurangi penggunaan kendaraan pribadi masyarakat. Sehingga berjalan kaki dijadikan sebagai moda transportasi utama yang menghubungkan antara suatu transportasi umum yang satu ke yang lainnya.

Untuk penelitian selanjutnya diharapkan mengkaji lebih banyak referensi bila perlu melakukan observasi lapangan secara langsung agar hasil penelitian yang didapat lebih baik dan lebih lengkap. Menambah responden agar hasil yang didapat lebih valid. untuk menambah faktor-faktor indeks walkability yang membutuhkan peninjauan langsung agar meningkatkan kuesioner agar hasil yang didapatkan lebih beragam dan lengkap.

\section{DAFTAR PUSTAKA}

D’Orso, G., \& Migliore, M. (2020). A GIS-based method for evaluating the walkability of a pedestrian environment and prioritised investments. Journal of Transport Geography, 82(June 2018)

Liu, Y., Yang, D., Timmermans, H. J. P., \& de Vries, B. (2020). The impact of the street-scale built environment on pedestrian metro station access/egress route choice. Transportation Research Part D: Transport and Environment, 87(August)

Schafer A. (1998). Transportation Research Part A: Policy and Practice, 1998, vol. 32, issue 6, 455-477

Kusbiantoro, B. S. (2006). Kebutuhan dan Peluang Pengembangan Fasilitas Pedestrian Pada Sistem Jalan di Perkotaan. LPPM, ITB.

Putranto, L. S., \& Khuana, R. B. (2021) . Analisis Indeks Walkability dalam Menilai Kualitas Jalur Pejalan Kaki Terhadap Keinginan Berjalan Kaki Dari dan Menuju Stasiun Transportasi Umum. Tarumanagara International Conference on the Application of Technology and Engineering.

McLeod S., Scheurer J., Curtis C. (2017) Urban Public Transport: Planning Principles and Emerging Practice. Journal of Planning Literature 1-17 